\title{
Reduction of High-Titer Cold Agglutinins by Plasmapheresis to Resolve Serological Problem in a Patient
}

\author{
Yanhong Cheng, Yu Qin, Maohong Bian, Huiqin Wen, Bangqiang Zhu, Peng Yang* \\ Department of Blood Transfusion, The First Affiliated Hospital, Anhui Medical University, Hefei, China \\ Email: *yangpeng00812@163.com
}

How to cite this paper: Cheng, Y.H., Qin, Y., Bian, M.H., Wen, H.Q., Zhu, B.Q. and Yang, P. (2020) Reduction of High-Titer Cold Agglutinins by Plasmapheresis to Resolve Serological Problem in a Patient. Case Reports in Clinical Medicine, 9, 247-254. https://doi.org/10.4236/crcm.2020.98035

Received: August 3, 2020

Accepted: August 24, 2020

Published: August 27, 2020

Copyright $\odot 2020$ by author(s) and Scientific Research Publishing Inc. This work is licensed under the Creative Commons Attribution International License (CC BY 4.0).

http://creativecommons.org/licenses/by/4.0/

\begin{abstract}
Background: Cold agglutinins are auto-antibodies that can be a nuisance in cross matching and in blood grouping. Here we report an unusual case of a high titer and wide amplitude cold agglutinin reduced by plasmapheresis. Methods and Materials: A 56-year-old man with severe anemia requested a transfusion of red blood cells. However, there was a problem in blood for blood grouping. The discrepancy of blood typing was subsequently resolved using group $\mathrm{O}$ absorbed plasma along with repetition of forward grouping with warm-washed red blood cells. The presence of high-thermal-amplitude and a high-titer anti-I cold agglutinin were detected in further serologic investigation. It revealed reactivity against autologous and adult $\mathrm{O}$ red blood cells at $37^{\circ} \mathrm{C}$ by the thermal amplitude screening test, and demonstrated a very high titer of 65,536 against adult $\mathrm{O}$ cells by titration studies at $4^{\circ} \mathrm{C}$. The patient received two plasma exchange sessions of 1.5 plasma volumes each. There was a significant reduction of the titer of cold agglutinins and of the thermal amplitude by plasmapheresis as well $(p<0.01)$. Results: After successful cross-matching with post plasma exchanges, four units of red blood cells were infused to the patient without any hemolysis symptoms or signs. Conclusions: We now reported a patient with abnormally ascended titer of cold agglutinins and wide-thermal-amplitude, but we also successfully performed $\mathrm{ABO}$ typing and cross matching after 2 plasma exchange sessions of 1.5 plasma volumes each.
\end{abstract}

\section{Keywords}

Cold Agglutinin, Plasmapheresis, Transfusion 


\section{Introduction}

Cold agglutinin, which was first described in 1903, and about approximately $25 \%$ of autoimmune hemolytic anemias (AIHA) was led by it [1] [2]. Cold agglutinins are antibodies that bind to erythrocyte surface antigens at low temperatures, and then can cause agglutination and complement-mediated hemolysis [2]. The low titer cold agglutinins are often detected in healthy individuals, and most of them are benign [3]. Pathological cold autoantibodies of high antibody titers and/or broad thermal amplitude, may be important clinical significance and cause acute or chronic hemolysis [4]. The immunoglobulin $\mathrm{M}$ antibodies usually specificity to carbohydrate antigens, are most commonly in blood group Ii [5].

The VH4-34 gene segment can encode the specific for the I/i RBCs membrane systems [6]. The same gene segment also can encode bacterial anti-lipopolysaccharide activity and other specificities. B cells containing VH4-34 gene sequence constitute part of the innate immune system, which were participated in the first line of defense against pathogens. Patients with cold agglutinins frequently accompany acute infectious diseases, such as Epstein-Barr viral infection, Mycoplasma pneumoniae pneumonia and lymphoproliferative disorders [1] [6]. The mechanism may be that the pathogen modifies the I active receptor on sialic acid to make it immunogenic, so that the body produces antibodies to this modified structure [6].

Cold agglutinins react the strongest at $2^{\circ} \mathrm{C}-5^{\circ} \mathrm{C}$, however, its binding may occur at temperatures approaching normal body temperature of mammals, which depends on the thermal amplitude of the antibody [7]. High titer cold antibodies can agglutinate red cells from the most human adults, including autologous red cells from the patient [7] [8]. However, the presence of cold agglutinins may cause problems in blood $\mathrm{ABO} / \mathrm{Rh}$ typing and cross matching for patients requiring transfusion [8].

We now reported a patient with abnormally ascended titer of cold agglutinins and wide-thermal-amplitude, but we also successfully performed $\mathrm{ABO}$ typing and cross matching after 2 plasma exchange sessions of 1.5 plasma volumes each.

\section{Case Report}

A 56-year-old male of Han nationality presented to the Hematology Department of our hospital with symptoms of extreme asthenia. At admission, he was very pale with evidently undernourished and the BP (blood pressure) was 80/50 mmHg. In addition, he was dyspnoeic and tachycardiac $(110 \mathrm{bpm})$ at rest. Heart sounds soft, but there is no other pathologic sign concerning his lungs and abdomen. In the past months, he had complained about cough. Routine blood test revealed a white blood cell count of $8.28(4-10) \times 10^{9} / \mathrm{L}$, platelet count of 134 $(100-300) \times 10^{9} / \mathrm{L}$, hemoglobin of $48(120-170) \mathrm{g} / \mathrm{L}$, however, the hematocrit, mean corpuscular volume, and the number of red blood cells could not be measured because of the interference by agglutinated erythrocytes. A lactic de- 
hydrogenase (LDH) level of $320 \mathrm{U} / \mathrm{L}$ (normal value, 120 - $150 \mathrm{U} / \mathrm{L}$ ), total bilirubin level of $135.70 \mu \mathrm{mol} / \mathrm{L}$ (normal value, $5.10-19.0 \mu \mathrm{mol} / \mathrm{L}$ ), and indirect bilirubin level of $110.20 \mu \mathrm{mol} / \mathrm{L}$ (normal value, $3.40-12.30 \mu \mathrm{mol} / \mathrm{L}$ ) were consistent with hemolytic anemia. Since the patient was severe anemic the hematologist requested for 2 units suspended red blood cells (RBCs).

Blood samples were sent to Blood Transfusion Department for cross match at once. Forward grouping results showed $4+$ agglutination with anti-A, anti-B and anti-D and reverse grouping results (at $25^{\circ} \mathrm{C}$ ) showed $4+$ agglutination with $\mathrm{A}, \mathrm{B}$ and $\mathrm{O}$ reagent cells. Antibody screening results also showed 4+ agglutination of all screening cells. The direct antiglobulin test (DAT) was performed by a gel-card format along with an auto-control and both were positive $(4+)$. Blood sample was grossly visible observed autoagglutination after collection. Blood sample showed enhanced autoagglutination by $30 \mathrm{~min}$ incubation at $4^{\circ} \mathrm{C}$. Since these observations were suggestive of cold agglutinins, patient's red blood cells were washed with warm saline thrice to remove cold antibodies in residual plasma. B positive blood group was showed by forward grouping test which used ABD reverse diluent card. The result of reverse grouping by using pre-warmed plasma (plasma was incubation at $37^{\circ} \mathrm{C}$ for $1 \mathrm{~h}$ ) was still inconsistent with forward grouping. Due to this blood typing discrepancy, the patient's plasma was adsorbed thrice with group $\mathrm{O}$ RBCs for $1 \mathrm{~h}$ at $37^{\circ} \mathrm{C}$. Blood grouping was repeated with group $\mathrm{O}$ adsorbed plasma. Now the agglutination with $\mathrm{B}$ and $\mathrm{O}$ cells disappeared. Then cross match was performed the by gel-card format and two compatible RBC units for transfusion. Cross match with two erythrocyte units (type B, D+) showed 4+ incompatibility and when cross-matching was repeated with prewarmed plasma, the same cells still showed $3+$ incompatibility.

Given the possibility of cold agglutinins, the thermal amplitude screening tests were performed. The presence of a high-thermal-amplitude with I specificity was revealed in further investigation which was strongly reactive (4+) against adult $\mathrm{O}$ and autologous RBCs but not against $\mathrm{O}$ cord cells at $4^{\circ} \mathrm{C}, 25^{\circ} \mathrm{C}$, and $30^{\circ} \mathrm{C}$; after incubation at $37^{\circ} \mathrm{C}$, the agglutination decreased markedly $(1+)$ with adult $\mathrm{O}$ and autologous RBCs (Table 1 ). Interestingly, the cold agglutinin titer at $37^{\circ} \mathrm{C}$ was still 2 when reacted against pooled adult O RBCs. The decrease of incubation temperature resulted in a significant increase of titer value. The highest titer was 65,536 at $4^{\circ} \mathrm{C}$, when tested against adult blood $\mathrm{O}$ type or autologous RBCs (Table 2). To sum up, our hypothesis were consistent with the data that the patient's high-thermal-amplitude and high titer cold agglutinins interfered with $\mathrm{ABO}$ typing and cross matching test.

Hematologist decided to reduce autoantibody titer by plasma exchange when the wide-thermal-amplitude and high titer cold agglutinins were discovered in the patient. One session of plasmapheresis was performed every other day, and two sessions of plasmapheresis were finally performed in two days.

A COBE Spectra Blood separator was used to involve continuous flow plasma exchange, 1.5 plasma volumes were replaced each time with a combination of 
$5 \%$ albumin in $0.9 \%$ saline. After commencing plasmapheresis, cold autoantibody levels rapidly decreased to half or less and cold agglutinin titers at $4^{\circ} \mathrm{C}$ dropped from 65,536 to 2048 (Table 2).

The blood was retaken $12 \mathrm{~h}$ after the second plasmapheresis and performed cross-matched test, which showed a compatible cross match with 4 units RBCs (type B, D+) were safely infusion using a blood warmer. Two days later, the transfusion had an expectedly results and his $\mathrm{Hb}$ levels had been increased by 19 g/L. Furthermore, the patient's posttransfusion indirect bilirubin level had decreased to $36.60 \mu \mathrm{mol} / \mathrm{L}$ and the $\mathrm{LDH}$ was $280 \mathrm{U} / \mathrm{L}$.

Table 1. Serologic findings in a patient with a hemolytic anti-I autoantibody and high thermal-amplitude: reactivity at different temperatures.

\begin{tabular}{ccccc}
\hline Target RBCs & $4^{\circ} \mathrm{C}$ & $25^{\circ} \mathrm{C}$ & $30^{\circ} \mathrm{C}$ & $37^{\circ} \mathrm{C}$ \\
\hline OI & $4+$ & $4+$ & $4+$ & + \\
Oi & 0 & 0 & 0 & $\mathrm{NT}$ \\
Auto & $4+$ & $4+$ & $4+$ & + \\
\hline
\end{tabular}

The $30^{\circ} \mathrm{C}$ and $37^{\circ} \mathrm{C}$ reactions were carried out with albumin $(22 \% \mathrm{wt} / \mathrm{vol})$ enhancement. All other incubations were carried out without an enhancing agent. Auto = autologous red blood cell; OI = adult group O RBCs; Oi = umbilical cord type O blood red blood cell; NT = not tested.

Table 2. Titration of the patient's plasma prior to treatment and after 2 sessions of plasma exchange.

\begin{tabular}{|c|c|c|c|}
\hline \multirow{2}{*}{ Target RBCs } & \multirow{2}{*}{ Temperature $\left({ }^{\circ} \mathrm{C}\right)$} & \multicolumn{2}{|c|}{ Titer value } \\
\hline & & Prior to PE & After 2 sessions of $\mathrm{PE}$ \\
\hline \multirow{5}{*}{ OI } & 4 & 65,536 & 2048 \\
\hline & 25 & 1024 & 128 \\
\hline & & & \\
\hline & 30 & 128 & 32 \\
\hline & 37 & 2 & 0 \\
\hline \multirow{5}{*}{$\mathrm{Oi}$} & 4 & 8 & 0 \\
\hline & 25 & 0 & 0 \\
\hline & & & \\
\hline & 30 & 0 & NT \\
\hline & 37 & 0 & NT \\
\hline \multirow{5}{*}{ Auto } & 4 & 65,536 & 1024 \\
\hline & 25 & 512 & 16 \\
\hline & & & \\
\hline & 30 & 64 & 4 \\
\hline & 37 & 1 & 0 \\
\hline
\end{tabular}

Patient plasma was serially diluted in normal saline. The titer reflects the highest titer at which $1+$ or greater agglutination was observed. Auto $=$ autologous red blood cell; OI = adult group O RBCs; Oi = umbilical cord group O blood red blood cell; NT = not tested. 
All serological test samples were anticoagulated with ethylenediaminetetraacetate following the procedure described in the AABB Technical manual [9]. $\mathrm{ABO}$ blood typing and $\mathrm{Rh}(\mathrm{D})$ phenotyping were performed with Column agglutination technique (DiaMed Diagnostics, Cressier FR, Switzerland). The antibody screen was performed with three screen reagent RBCs (Ortho-Clinical Diagnostics, Inc. Raritan, NJ, USA) in a gel-card format (DiaMed). The indirect antiglobulin test (IAT) and the direct antiglobulin test (DAT) were performed with a monospecific anti-immunoglobulin $\mathrm{G}(\mathrm{IgG})$ reagent without an enhancing agent and a gel-card format from DiaMed, respectively.

Cold agglutinin titers were performed using gradient dilution method. Briefly, $200 \mu \mathrm{L}$ sera were serially diluted in the same volume $0.9 \%$ saline, mixed with 0.2 $\mathrm{ml} 1 \%$ group $\mathrm{O}$ red cells. Incubation was at indicated temperature for $1 \mathrm{~h}$ followed by centrifugation for $1 \mathrm{~min}$ at $1000 \times \mathrm{g}$. The titer values were defined as the highest dilution in which a $1+$ reaction was observed. Test for cold agglutinin absorption was done by tube testing. One volume of serum was absorbed with twice the volume of packed $\mathrm{O}$ red cells. Following incubation for $1 \mathrm{~h}$ at $4^{\circ} \mathrm{C}$, the serum was separated from the mixture.

A thermal amplitude screening test with neat plasma was performed at $30^{\circ} \mathrm{C}$ and $37^{\circ} \mathrm{C}$, group $\mathrm{O}$ red cells were enhanced with albumin $(22 \% \mathrm{wt} / \mathrm{vol})$, incubation was at indicated temperature for $1 \mathrm{~h}$ followed by centrifugation for $1 \mathrm{~min}$ at $1000 \times \mathrm{g}$.

\section{Discussion}

Usually, the cold agglutinin is considered to have no clinically significant because of its low thermal amplitude. The thermal amplitude refers to the highest temperature at which the cold agglutinin reacts with the antigen. When the thermal amplitude exceeds $28^{\circ} \mathrm{C}$ to $31^{\circ} \mathrm{C}$, erythrocytes may agglutinate in acral parts of the body even at mild temperatures, and often leading to complement binding and complement-mediated hemolysis [1] [7]. Interestingly, when the patient's blood sample was first identified, the anti-I autoantibody react at IAT phases, $37^{\circ} \mathrm{C}$, against O-type red blood cells and/or autologous, which was consistent with the evidence of hemolytic in the laboratory. Cold autoantibodies of low titer are common and often found in normal individuals. However, they can be a nuisance in blood grouping and cross-matching [5] [8], as in this case. Reverse grouping was not concordant with forward typing, and the 3 panel cells were reactive with a positive auto-control which may suggest the possible presence of alloantibodies. Subsequent serological examination revealed the exact presence of a high-titer and high-thermal-amplitude cold agglutinin. Forward typing was performed after washing patient's blood cells with warm water and reverse typing was performed with pre-warmed plasma, however, the results of forward and reverse typing were still conflicting. Therefore, the blood grouping when repeated using group $\mathrm{O}$ absorbed plasma and warm-washed $\mathrm{RBC}$, resolved blood typing discrepancy and the patient was group B. 
Unfortunately, reactivity against autologous and adult $\mathrm{O}$ red blood cells at $37^{\circ} \mathrm{C}$ were revealed by the thermal amplitude screening test, and a very high titer of 65,536 against adult $\mathrm{O}$ cells at $4^{\circ} \mathrm{C}$ by titration studies. In general, the pathogenicity of cold agglutinin depends more on the degree of the thermal amplitude rather than on the titer [10] [11]. However, titer levels above 512 at $4^{\circ} \mathrm{C}$ are considered to be clinically significant [12]. Berentsen and colleagues described a median titer of 2048 among 86 patients with cold agglutinin disease, in a study from Norway [13]. Similarly, Stone and associates observed titers ranging from 512 to 65,536 among 172 patients with the same disease [12]. In this case, the titer level of cold agglutinin was 65,536 at $4^{\circ} \mathrm{C}$, and 128 at $30^{\circ} \mathrm{C}$, the results suggested the exist of the potential antibody which could disturb blood grouping and cross matching, might the risk of in vivo hemolysis. Laboratory data from patients and subsequent serological test confirmed this concern.

The cold agglutinins involved are usually IgM class, less common are IgA or IgG class. They usually agglutinate with RBCs at temperatures ranging from $2^{\circ} \mathrm{C}$ to $5^{\circ} \mathrm{C}$, even they may also agglutinate at normal body temperature [14] [15]. Cold agglutinin can cause complement activation at a low temperature in acral and peripheral circulation of the body, and complement cascade -mediated hemolysis will ensue. This case had IgM autoantibody and the cold agglutinin reacted at $37^{\circ} \mathrm{C}$, and with stronger reaction at $4^{\circ} \mathrm{C}$. So, we could not confirm the class of the cold agglutinin.

However, the presence of cold agglutinins may cause problems in cross matching and the management of surgery for patients. Many preoperative measures such as interferon -2 , immunosuppressive therapy, and plasma exchange were attempted to decrease the concentration of cold antibodies in vivo [14] [16]. This case man was managed with two sessions of plasmapheresis and 3 plasma volumes were replaced. As expected, the plasmapheresis resulted in a reduction of one or two steps of cold autoantibody reactivity at $4^{\circ} \mathrm{C}, 20^{\circ} \mathrm{C}, 25^{\circ} \mathrm{C}$, $30^{\circ} \mathrm{C}$ and $37^{\circ} \mathrm{C}$ respectively when against $\mathrm{O}$ type cells. Base on this finding, we done cross match with using patient plasma after replacement and then showed compatible with B positive RBC units. The patient was safely infused with 4 units of RBCs and was discharged.

\section{Conclusion}

Pathological cold agglutinin disease may be related to different degrees of thermal amplitude and titer. In summary, although it is not necessary to detect examples of cold agglutinins that only react below body temperatures, they are deserve considering in the context of appropriate serological when there are broad thermal amplitudes and high titers. Importantly, the case described by Koike [14] demonstrated, therapeutic plasma exchange may result in a significant decrease of the titer of cold agglutinins and the thermal amplitude, which is benefit to the solution of serological problems. The dramatic case provides further evidence on the clinical relevance of high-thermal-amplitude, a high-titer cold ag- 
glutinin. In addition, therapeutic plasma exchange may be a significant reduction of the thermal amplitude and the titer of cold agglutinins which facilitate the solution of serological problems.

\section{Acknowledgements}

This work was supported by Natural Sciences Foundation of Anhui Province (1808085MH273).

\section{Conflicts of Interest}

The authors have disclosed no conflicts of interest.

\section{References}

[1] Berentsen, S. (2009) Cold Agglutinin-Mediated Autoimmune Hemolytic Anemia in Waldenstrom's Macroglobulinemia. Clinical Lymphoma and Myeloma, 9, 110-112. https://doi.org/10.3816/CLM.2009.n.030

[2] Berentsen, S., Randen, U. and Tjonnfjord, G.E. (2015) Cold Agglutinin-Mediated Autoimmune Hemolytic Anemia. Hematology/ Oncology Clinics of North America, 29, 455-471. https://doi.org/10.1016/j.hoc.2015.01.002

[3] Berentsen, S. and Tjonnfjord, G.E. (2012) Diagnosis and Treatment of Cold Agglutinin Mediated Autoimmune Hemolytic Anemia. Blood Reviews, 26, 107-115. https://doi.org/10.1016/j.blre.2012.01.002

[4] Wongsaengsak, S., Czader, M. and Suvannasankha, A. (2018) Cold Agglutinin-Mediated Autoimmune Haemolytic Anaemia Associated with Diffuse Large B cell Lymphoma. BMJ Case Reports, 2018, bcr2017222064. https://doi.org/10.1136/bcr-2017-222064

[5] Darabi, K. and Makar, R.S. (2008) Acute Hemolysis of Transfused A2 Red Cells by an Auto-HI Antibody. Transfusion, 48, 964-968.

https://doi.org/10.1111/j.1537-2995.2008.01661.x

[6] Randen, U., Troen, G., Tierens, A., Steen, C., Warsame, A., Beiske, K., et al. (2014) Primary Cold Agglutinin-Associated Lymphoproliferative Disease: A B-Cell Lymphoma of the Bone Marrow Distinct From Lymphoplasmacytic Lymphoma. Haematologica, 99, 497-504. https://doi.org/10.3324/haematol.2013.091702

[7] Berentsen, S. (2016) Cold Agglutinin Disease. Hematology-American Society of Hematology Education Program, 2016, 226-231. https://doi.org/10.1182/asheducation-2016.1.226

[8] Berentsen, S. (2011) How I Manage Cold Agglutinin Disease. British Journal of Haematology, 153, 309-17. https://doi.org/10.1111/j.1365-2141.2011.08643.x

[9] Brecher, M.E. (2005) Technical Manual. 15th Edition, American Association of Blood Banks, Bethesda, Maryland, USA.

[10] Al-Dorzi, H.M., Salama, H., Almugairi, A. and Arabi, Y.M. (2017) Cold Agglutinin Disease: An Unusual Cause of Shock in the ICU. Intensive Care Medicine, 43, 927-928. https://doi.org/10.1007/s00134-016-4668-x

[11] Roelcke, D., Dahr, W. and Kalden, J.R. (1986) A Human Monoclonal IgM K Cold Agglutinin Recognizing Oligosaccharides with Immunodominant Sialyl Groups Preferentially at the Blood Group M-Specific Peptide Backbone of Glycophorins: Anti-Pr ${ }^{\mathrm{M}}$. Vox Sanguinis, 51, 207-211. https://doi.org/10.1111/j.1423-0410.1986.tb01954.x 
[12] Stone, M.J., McElroy, Y.G., Pestronk, A., Reynolds, J.L., Newman, J.T. and Tong, A.W. (2003) Human Monoclonal Macroglobulins with Antibody Activity. Seminars in Oncology, 30, 318-324. https://doi.org/10.1053/sonc.2003.50077

[13] Berentsen, S., Ulvestad, E., Langholm, R., Beiske, K., Hjorth-Hansen, H., Ghanima, W., et al. (2006) Primary Chronic Cold Agglutinin Disease: A Population Based Clinical Study of 86 Patients. Haematologica, 91, 460-466.

[14] Koike, .Y, Akiyama, Y. and Utani, A. (2014) Cold Agglutinin Disease-Associated Digital Gangrene Treated with Plasmapheresis. Indian Journal of Dermatology, Venereology and Leprology, 80, 575-576. https://doi.org/10.4103/0378-6323.144221

[15] Shamshad, G.U., Salamat, N. and Umair, M. (2017) Cold Agglutinin Disease in a Patient of Pulmonary Tuberculosis. Journal of the College of Physicians and Surgeons Pakistan, 27, S92-S94.

[16] Raut, M., Joshi, S. and Maheshwari, A. (2017) Cold Agglutinin-Diagnose It before Cardiac Surgery. Journal of Cardiothoracic and Vascular Anesthesia, 31, E11. https://doi.org/10.1053/j.jvca.2016.09.024 